\title{
TROTE PELO AMANHÃ: UMA NOVA FORMA DO INGRESSANTE VIVER A SUA PRIMEIRA EXPERIÊNCIA UNIVERSITÁRIA
}

DOI: 10.37702/2175-957X.COBENGE.2021.3523

Maira Gazzi Manfro - mairagmanfro@gmail.com

Universidade Federal do Rio Grande do Sul

Rua Valdir Gasperin 31

95032-733 - Caxias do Sul - RS

Júlia Nicolao Piacentini - jnicolaopiacentini@gmail.com

Universidade Federal do Rio Grande do Sul

Av. Presidente Vargas 318

95720-000 - Garibaldi - RS

Júlia Battaglin Pierdoná - Julia.battaglin@hotmail.com

Universidade Federal do Rio Grande do Sul

Rua Dona Augusta 202

90850-130 - Porto Alegre - RS

Larissa Pereira Duarte - larissaduarte467@gmail.com

Universidade Federal do Rio Grande do Sul

Rua Vidal de Negreiros, 284, São José, Porto Alegre-RS 284

91520-480 - Porto Alegre - RS

Pedro Rafael Borba Leal - pedro06leal@gmail.com

Universidade Federal do Rio Grande do Sul

rua Morro Alto 428

91751-650 - Porto Alegre - RS

Resumo: Este artigo apresenta a trajetória de construção do projeto Trote pelo Amanhã, focado especialmente nos ingressantes dos cursos de engenharia da Universidade Federal do Rio Grande do Sul (UFRGS). Os trotes universitários foram instalados no Brasil juntamente com a consolidação das universidades. Ao longo dos anos, o trote passou a ser ressignificado, tornando-se um movimento de descontração e de inclusão. O projeto Trote pelo Amanhã possui como objetivo principal ser um agente de transformação, resultando em uma UFRGS mais sustentável e permitindo que os ingressantes tenham um papel ativo na 
universidade desde o início de sua trajetória, obtendo experiências únicas em sua vida acadêmica. Ele funciona a partir da formação de equipes, que devem arrecadar resíduos sólidos recicláveis e ajudar na construção de objetos a partir desses materiais. 0 projeto foi dividido em 6 etapas de execução: (1) liberação do formulário de inscrição, (2) semana de conscientização, (3) recebimento dos resíduos sólidos recicláveis, (4) início da construção dos objetos, (5) premiação das equipes vencedoras e (6) criação de um espaço de convivência. Como validação do projeto, realizou-se uma pesquisa em que, a partir dos resultados, foi constatado que mais de $50 \%$ dos veteranos e mais de $70 \%$ dos ingressantes sentem falta de um contato mais próximo entre estudantes. Pode-se concluir que essa integração será alcançada através do Trote pelo Amanhã, onde os ingressantes conhecerão colegas de curso e de outras engenharias. $O$ projeto piloto será implementado na UFRGS, tendo a perspectiva de expansão para outras universidades/cursos.

Palavras-chave: Trote solidário. Sustentabilidade. Integração. Escola de Engenharia UFRGS. Educação em Engenharia. 


\section{TROTE PELO AMANHÃ: UMA NOVA FORMA DO INGRESSANTE VIVER A SUA PRIMEIRA EXPERIÊNCIA UNIVERSITÁRIA}

\section{INTRODUÇÃO}

A Universidade Federal do Rio Grande do Sul (UFRGS) teve início em 1895 e, logo após um ano da fundação, originou-se a Escola de Engenharia. Esse núcleo é responsável pela representação de mais de 5.000 estudantes de graduação atualmente, distribuídos nos 13 cursos abrangidos. Por ano ingressam, em média, mais de 1.000 alunos nesses cursos de Bacharel em Engenharia, distribuídos entre os dois semestres letivos anuais (UFRGS, 2018).

A Escola de Engenharia possui diversos projetos que apoiam os ingressantes no início da sua trajetória na universidade. Um desses projetos, realizado pelo Núcleo de Ações Discentes - NADI, é o "Acolhimento dos Calouros - Desafio UFRGS", realizado semestralmente e aberto para todos os novos estudantes da Escola de Engenharia que queiram participar. Esse Desafio tem como objetivo instigar o calouro a propor projetos de melhorias, que tenham viés sustentável, abrangendo as esferas econômica, social e ambiental e ainda alinhar com os 17 Objetivos do Desenvolvimento Sustentável da ONU. Dentro desse Desafio, o projeto "Trote pelo Amanhã" foi elaborado e recebeu um dos 5 destaques disponibilizados pela comissão avaliadora (UFRGS, 2021).

Os trotes universitários foram instalados no Brasil entre os séculos XIX e XX, juntamente com a consolidação das universidades. Foram brasileiros que saíram do país para estudar em Portugal os primeiros a trazerem essa tradição para o país. Nessa época o trote era extremamente pejorativo e, muitas vezes, perigoso. Era a forma de mostrar a submissão dos calouros em relação aos veteranos, sendo de participação obrigatória. Um registro de 1831 apontou a morte de um estudante que se recusou a participar dessa prática e foi assassinado pelos seus então veteranos (GUTIERREZ, 2021).

Conforme os anos foram passando e a cultura do país foi se modificando, os trotes universitários sofreram um ressignificamento, deixando de ser algo tão drástico e passando a ser um momento de descontração e inclusão entre os estudantes. Mesmo assim, em algumas ocasiões, atos exagerados foram praticados. Um exemplo é o trote que ocorreu em 2013 na Universidade Federal do Rio Grande do Sul, organizado pelos veteranos do curso de Bacharelado em Engenharia Civil, em que os calouros foram obrigados a segurar uma cabeça de porco e receberam um banho de uma mistura contendo vísceras de peixe, ovos vencidos e farinha (FREITAS, 2013).

Desde esse ocorrido, a Escola de Engenharia emitiu uma nota oficial informando que apoiaria ações que fossem voltadas para a comunidade, como as iniciativas de trotes solidários. Foi então que, em 2015, os calouros do curso de Biblioteconomia foram "obrigados" pelos seus veteranos a contar histórias para crianças da creche da Vila Planetário, além de realizar a doação de livros. A partir desse momento algumas iniciativas de trotes solidários começaram a ter maior visibilidade dentro e fora da UFRGS (DUTRA, 2013) (VILANI, 2015).

Com o intuito de tornar essa prática solidária algo efetivo e próspero dentro da UFRGS, surge o projeto Trote pelo Amanhã, criado por cinco estudantes da Escola de Engenharia da Universidade Federal do Rio Grande do Sul. O projeto possui como objetivo principal se tornar um agente de transformação, resultando em uma UFRGS mais sustentável e permitindo que os ingressantes dos cursos de engenharia tenham um papel 
ativo na universidade desde o início de sua trajetória. Esses objetivos foram delimitados após a realização de pesquisas teóricas sobre pontos que poderiam ser melhorados dentro da universidade e também no núcleo da comunidade externa a ela.

De acordo com a pesquisa GreenMetric World University Rankings, realizada em 2020, "a Universidade Federal do Rio Grande do Sul ocupa a oitava posição entre as universidades brasileiras no ranking mundial de sustentabilidade e a $224^{a}$ no mundo". Esse dado demonstra que a universidade está no caminho certo, porém ainda tem aspectos a melhorar, de forma a se equiparar com as universidades de outros países. A melhor forma de conseguir expandir a sustentabilidade dentro da universidade é incentivando todos (ou a maioria) dos estudantes a contribuir para esse movimento e para um ambiente mais limpo e ambientalmente responsável (UFRGS, 2020).

Em relação aos ingressantes, a UFRGS possui projetos de acolhimento, como o Desafio dos Calouros, porém a aderência dos estudantes a esses projetos ainda não é tão expressiva. O primeiro contato do ingressante com a universidade é extremamente importante, pois define como ele irá reagir frente a situações adversas e a quem solicitará ajuda. A universidade é um mundo totalmente novo quando comparado ao ensino médio e os estudantes precisam de uma boa base nesse primeiro contato que é único na vida acadêmica de cada um.

O Trote do Amanhã vem como um projeto capaz de unir ambas as lacunas: difundir a cultura de sustentabilidade dentre os estudantes e fornecer o suporte inicial que os ingressantes necessitam. O projeto é realizado com base na formação de equipes de calouros e veteranos, tendo como objetivo a arrecadação de resíduos sólidos reaproveitáveis que serão transformados em objetos para os espaços de convivência da universidade. Dessa forma o projeto promove a educação ambiental, a comunicação entre calouros e veteranos, e a colaboração e criatividade na criação dos objetos produzidos a partir do reaproveitamento de materiais. Além disso, o projeto foca em colaborar para o atingimento de dois dos Objetivos do Desenvolvimento Sustentável (ODS): o objetivo número 11: cidades e comunidades sustentáveis, e o número 12: consumo e produção responsáveis (IBGE, 2021).

\section{METODOLOGIA}

Com o intuito de atingir com excelência o objetivo do projeto, e considerando a situação de pandemia em 2021, foi realizada uma pesquisa qualitativa online, elaborada pela equipe do projeto Trote pelo Amanhã. O formulário de pesquisa foi enviado para os calouros e os veteranos dos cursos que compõem a Escola de Engenharia da UFRGS e, a partir das respostas, delimitou-se as lacunas a serem abordadas ao longo da execução do Trote pelo Amanhã. $O$ envio e a divulgação do formulário foram realizados por meio das redes sociais de cada um dos membros e pelo e-mail oficial da Escola de Engenharia.

As questões da pesquisa qualitativa foram divididas entre respondentes veteranos e respondentes calouros, para posteriormente poder analisar melhor os dados coletados. O formulário continha 3 perguntas objetivas e 3 subjetivas para os calouros e 3 perguntas objetivas e 1 subjetiva para os veteranos. A partir das respostas foi possível analisar os seguintes aspectos: em qual campus os estudantes sentem uma necessidade maior de ter um espaço de convivência; qual o nível de satisfação dos estudantes em relação à integração que ocorre nos primeiros contatos entre ingressantes e veteranos; a intenção de participação dos estudantes em trotes solidários; e o interesse em receber uma premiação participando do Trote pelo Amanhã. 
A partir dos dados coletados, a equipe foi capaz de elaborar um plano de ação a ser colocado em prática assim que for possível a retomada de atividades presenciais na universidade. $O$ projeto Trote pelo Amanhã terá uma ocorrência semestral, ou seja, cada vez que a universidade recebe novos ingressantes. O projeto se divide em 6 fases.

\subsection{Fase I - Liberação do formulário de inscrição}

No dia em que os calouros realizam a matrícula presencial na universidade, uma semana antes de começar as aulas, o projeto Trote pelo Amanhã se inicia. Através de um formulário online os ingressantes e veteranos informam a sua intenção de participar do evento e se possuem algum conhecido que gostariam que estivesse na mesma equipe. $O$ formulário fica aberto por seis dias e uma divulgação intensa é realizada nas redes sociais do projeto e da Escola de Engenharia.

\subsection{Fase II - Semana de conscientização e informação}

Juntamente com o lançamento do formulário, inicia-se a semana de educação ambiental, com palestras e minicursos, objetivando a conscientização do maior número de estudantes sobre a temática da sustentabilidade. No último dia da semana são divulgadas as equipes que foram formadas pela comissão, utilizando dados do formulário preenchido pelos estudantes, e que seguirão unidas até o final do evento.

\subsection{Fase III - Recebimento dos resíduos sólidos reaproveitáveis e recicláveis}

A partir da semana seguinte se inicia a arrecadação dos resíduos sólidos recicláveis. Cada resíduo possui uma pontuação específica, previamente divulgada, que será anotada na planilha de controle referente a cada uma das equipes participantes. Alguns exemplos de resíduos aceitos: garrafas pet, pneus, paletes, caixa de leite e caixa de sapato.

\subsection{Fase IV - Início da construção dos objetos}

Na terceira semana começa a fase de construção dos objetos, em que cada objeto construído também gera uma pontuação para a equipe, previamente divulgada, de acordo com a dificuldade de fabricação do mesmo. Alguns exemplos de objetos a serem fabricados: jogos de pebolim com caixa de leite, balanços de pneu, mesas com paletes e puffs com garrafas pet.

\subsection{Fase V - Premiação das equipes vencedoras}

$\mathrm{Na}$ semana que antecede o final do semestre, a arrecadação dos resíduos e a fabricação dos objetos se encerra e inicia a contagem dos pontos de cada equipe. Após a contagem, haverá um dia para a divulgação do TOP 3 do evento com a entrega das premiações informadas no início do evento. Essas premiações serão obtidas com entidades parceiras do projeto Trote pelo Amanhã.

\subsection{Fase VI - Criação do espaço de convivência}


Nas duas primeiras semanas de férias pós semestre, a comissão organizadora do projeto irá montar o espaço de convivência no local liberado pela Escola de Engenharia e ficará responsável pela sua manutenção.

\section{RESULTADOS E DISCUSSÃO}

A pesquisa qualitativa online obteve um total de 129 respostas, sendo 73 ingressantes e 56 veteranos. Os resultados principais são exibidos nesta seção.

\subsection{Respostas dos veteranos ao questionário}

A Figura 1 e a Figura 2 apresentam as perguntas específicas propostas no questionário, o número de respondentes e os resultados percentuais das respostas dos veteranos às perguntas propostas no questionário.

Figura 1 - Veteranos que sentem falta de um espaço de convivência no campus Centro

Você sente falta de um espaço onde as pessoas possam interagir livremente no Campus

CENTRO?

53 respostas

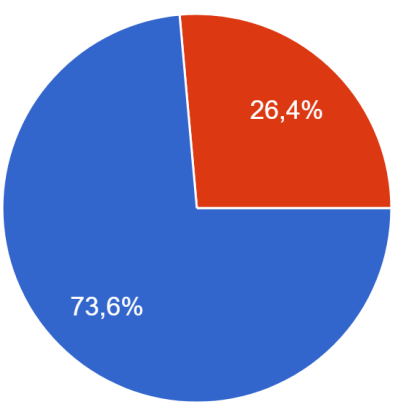

Fonte: Autores (2021) 
Figura 2 - Veteranos que sentiram falta de uma maior integração no seu ingresso na UFRGS

Você sentiu falta de uma integração maior entre os calouros e/ou entre os calouros e os veteranos quando você entrou na UFRGS?

56 respostas

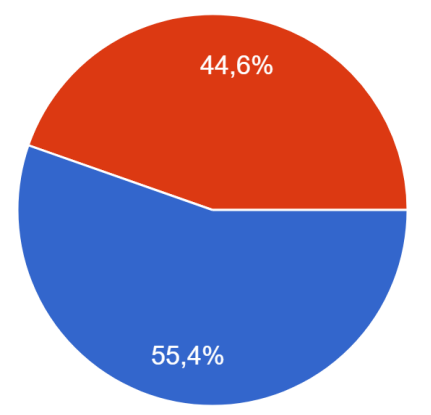

Analisando os resultados apresentados nas Figuras 1 e 2 é possível observar que os veteranos, mesmo aqueles que ainda não tiveram um contato tão próximo com os espaços físicos da universidade, sentem que seria necessário criar mais espaços de convívio dentro das instalações dos campi. Além disso, verificou-se que mais de $50 \%$ dos veteranos sentem falta de uma integração maior quando ingressam na universidade.

Ao perguntar "Caso você tivesse participado de um trote que construísse um legado para a UFRGS, o que você acha que seria diferente?", algumas respostas marcantes foram obtidas, podendo ser resumidas em duas citações:

- "Teria criado um vínculo mais forte com a Universidade, o que iria me motivar mais a participar das atividades da universidade";

- "Teria conhecido os outros bixos e interagindo melhor com meus veteranos e provavelmente me sentindo melhor acolhida".

Esses dois estudantes representam o sentimento que mais foi demonstrado na pesquisa: a necessidade de se sentir parte da universidade e parte de um grupo.

\subsection{Respostas dos ingressantes ao questionário}

As Figuras 3 e 4 apresentam os resultados das respostas dos ingressantes, mostrando as perguntas específicas, o número de respondentes e a distribuição percentual das respostas. 


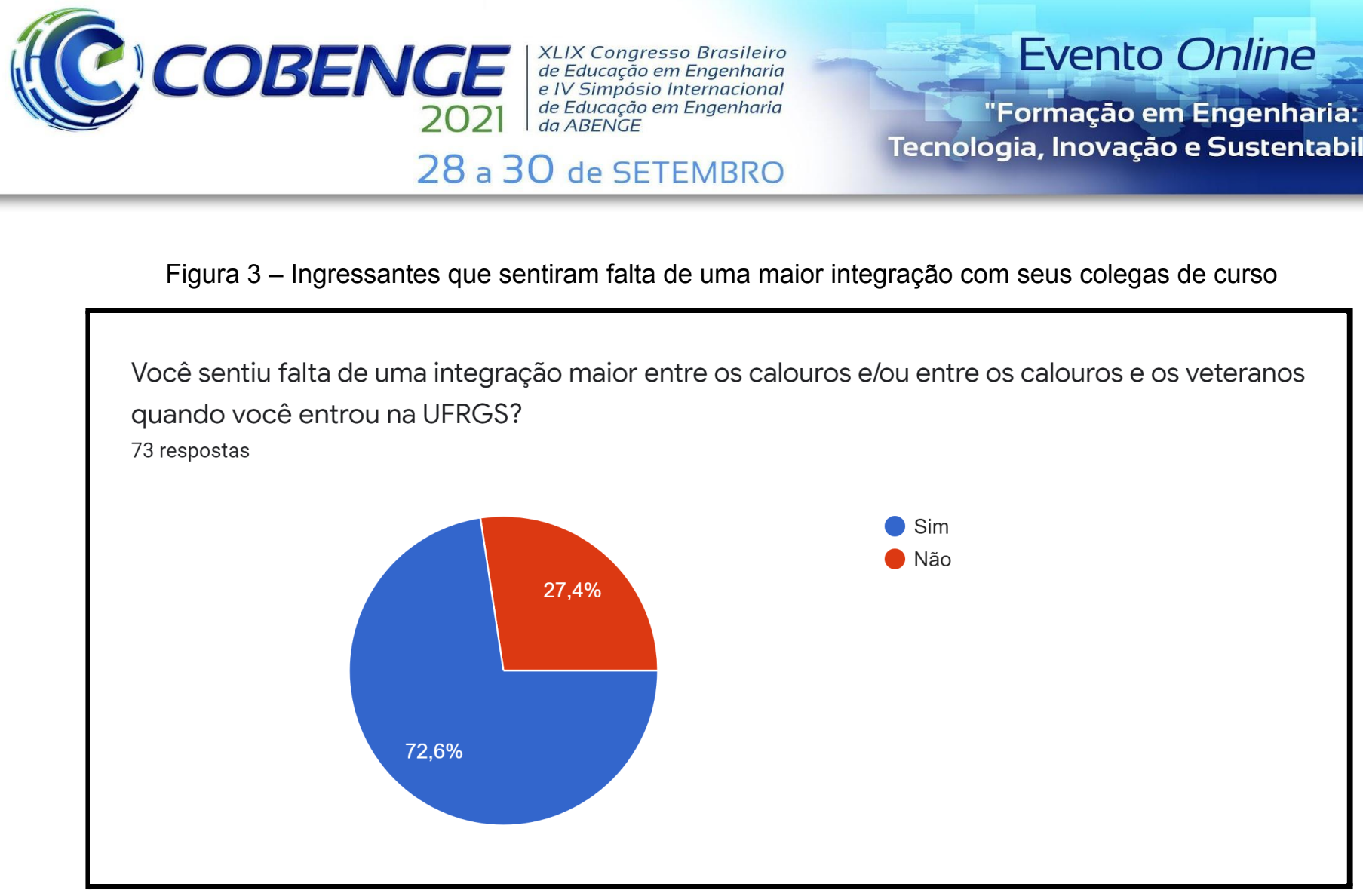

Fonte: Autores (2021)

Figura 4 - Ingressantes que participariam de um trote que deixasse um legado

Você participaria de um trote que deixasse um legado a ser utilizado pela comunidade acadêmica?

73 respostas
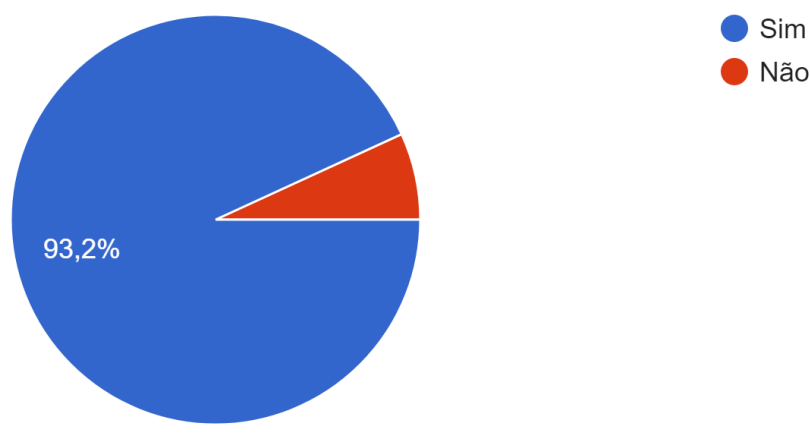

Fonte: Autores (2021)

Analisando os resultados apresentados nas Figuras 3 e 4, foi verificado de maneira expressiva que os ingressantes sentem uma falta de integração com seus veteranos e até mesmo com seus colegas de curso. Mais de $70 \%$ demonstra sentir essa deficiência no que tange à integração entre estudantes. Além disso, mais de $90 \%$ participaria de um trote que deixasse um legado na universidade, mostrando que o projeto Trote pelo Amanhã está no caminho certo para realizar essa transformação na UFRGS. 


\section{CONSIDERAÇÕES FINAIS}

Diante da pesquisa qualitativa realizada e através dos feedbacks recebidos pelos jurados do evento Acolhimento dos Calouros - Desafio UFRGS, obteve-se a primeira validação oficial de que o projeto Trote pelo Amanhã está com a sua proposta bem estabelecida e pronto para ter seu primeiro teste prático realizado.

Para conseguir realizar esse teste é estabelecido um cronograma de próximos passos a serem executados. A curto prazo, planeja-se adequar o projeto para o ambiente virtual, uma vez que a previsão para o próximo semestre (2021/01) na Universidade Federal do Rio Grande do Sul é continuar com as atividades em regime remoto. Dessa forma, deseja-se promover atividades voltadas à sustentabilidade e manter a gamificação do evento, tendo alguma premiação final para as equipes com melhores colocações.

A longo prazo, almeja-se poder implementar o projeto presencialmente e fazer o primeiro teste inicial, coletando feedback dos estudantes, ingressantes e veteranos, e analisando quais pontos devem ser melhorados. Além disso, objetiva-se cumprir com duas parcerias que já foram estabelecidas para o início físico do projeto. A primeira parceria é com a SUINFRA (Superintendência de Infraestrutura da UFRGS), arrecadando mudas de plantas, sacos de terra e tintas para serem utilizados nas dependências da universidade. A segunda parceria é com a ENACTUS UFRGS (time de empreendedorismo social), arrecadando roupas, alimentos e outros materiais que possam ser destinados aos grupos sociais atendidos por eles.

O projeto piloto será implementado na UFRGS, porém, pretende-se expandir a ideia para mais universidades, e para uma maior rede de cursos, por meio da divulgação do presente projeto em eventos e nas redes sociais. Com isso, espera-se uma maior integração entre estudantes de diferentes universidades, ponto este que será estudado e validado ao longo da execução do projeto Trote pelo Amanhã.

\section{AGRADECIMENTOS}

A equipe Trote pelo Amanhã dedica esta aba do artigo para demonstrar o sentimento de gratidão a todos(as) que tornaram a criação desse projeto possível, desde os estudantes que participaram da pesquisa, até os avaliadores que estiveram presentes conosco durante o evento Acolhimento dos Calouros - Desafio UFRGS 2020/02. Nosso agradecimento especial aos mentores: Simone Ramires, Camila Simonetti, Mariana Brandão e ao nosso orientador: Fabiano Gasparin. Agradecemos também à Escola de Engenharia da UFRGS por nos proporcionar vivências como esta desde o nosso primeiro semestre na universidade.

\section{REFERÊNCIAS}

DUTRA, G1: Fabrício. Em nota, UFRGS diz que tomará medidas após trote polêmico. 2013. Disponível em:

http://g1.globo.com/rs/rio-grande-do-sul/noticia/2013/03/em-nota-engenharia-da-ufrgs-avis a-que-tomara-medidas-apos-trote.html. Acesso em: 05 maio 2021. 
FREITAS, G1: Caetanno. Em trote, calouros são obrigados a segurar cabeça de porco no RS. 2013. Disponível em:

http://g1.globo.com/rs/rio-grande-do-sul/noticia/2013/03/em-trote-calouros-sao-obrigadossegurar-cabeca-de-porco-no-rs-veja.html. Acesso em: 05 maio 2021.

GUTIERREZ, Penmcie: Matheus Naville. Trote e sua história no Brasil: da idade média, pela ditadura e hoje. Disponível em:

https://www.blogs.unicamp.br/pemcie/2018/06/19/historia-trote-brasil/\#: :text=0\%20trote \%20surgiu\%20juntamente\%20com,grande \%20maioria\%20dos\%20pa\%C3\%ADses \%20eu ropeus.\&text=J\%C3\%A1\%20nos $\% 20$ primeiros $\% 20$ registros $\% 20$ hist $\%$ C3\%B3ricos,e $\% 20 f$ oi\%20assassinado\%20pelos\%20veteranos.. Acesso em: 05 maio 2021.

IBGE. Indicadores Brasileiros para os Objetivos de Desenvolvimento Sustentável. Disponível em: https://odsbrasil.gov.br/. Acesso em: 05 maio 2021.

UFRGS, Escola de Engenharia. Acolhimento dos Calouros 2020/2. 2021. Disponível em: https://www.ufrgs.br/engenharia/acolhimento-dos-calouros-2020-2/. Acesso em: 05 maio 2021.

UFRGS, Escola de Engenharia. Apresentação da Escola. 2018. Disponível em: https://www.ufrgs.br/engenharia/apresentacao/. Acesso em: 05 maio 2021.

UFRGS. UFRGS sobe mais de 100 posições em ranking internacional de sustentabilidade. 2020. Disponível em:

http://www.ufrgs.br/ufrgs/noticias/ufrgs-sobre-mais-de-100-posicoes-em-ranking-internacio nal-de-sustentabilidade\#: :text=UFRGS\%20sobe $\% 20$ mais $\% 20 \mathrm{de} \% 20100 \% 20$ posi $\%$ C3\% A7\%C3\%B5es\%20em\%20ranking\%20internacional\%20de\%20sustentabilidade,-14\%2F12 \%2F2020\&text=A\%20UFRGS\%20ocupa\%20a\%20oitava,e\%20a\%20224\%C2\%AA\%20no \%20mundo.. Acesso em: 05 maio 2021.

VILANI, Gzh: Tadeu. No trote, bixos da UFRGS são "obrigados" a contar histórias a crianças. 2015. Disponível em:

https://gauchazh.clicrbs.com.br/porto-alegre/noticia/2015/03/no-trote-bixos-da-ufrgs-sao-o brigados-a-contar-historias-a-criancas-4720259.html. Acesso em: 05 maio 2021. 


\title{
C COBENCE \\ TROTE PELO AMANHÃ (HAZING FOR TOMORROW): A NEW WAY FOR THE FRESHMAN TO LIVE HIS FIRST UNIVERSITY EXPERIENCE
}

\begin{abstract}
This document presents the construction trajectory of the Trote pelo Amanhã project, focusing on the freshmen of the engineering courses at Universidade Federal do Rio Grande do Sul (UFRGS). The university hazings were installed in Brazil along with the university's consolidation. Over the years, the hazing starts to be reframed, creating an atmosphere of inclusion. The project has as the major goal being an agent of transformation, resulting in a sustainable UFRGS, allowing the freshmen to have an important and active role in the university since the beginning of their trajectory, collecting unique experiences in their academic life. It works from teams formation, and they have to collect recyclable solid residues and provide help in the construction of objects coming from these residues. It has been separated in 6 fases: (1) inscription form release, (2) week of awareness, (3) receipt of the recyclable solid residues, (4) beginning of the objects construction, (5) awarding of the winning teams and (6) creation of an espace to integration. To validate the project, a research was conducted and, with the results obtained, it could be established that more than $50 \%$ of the veterans and more than $70 \%$ of the freshmen misse a close integration. It could be concluded that this integration will be achieved through the Trote pelo Amanhã project, where the freshmen will be able to meet course colleagues and students from other engineering. The pilot project will be implemented at UFRGS, with the perspective of expansion to other universities and courses.
\end{abstract}

Keywords: Solidary hazing. Sustainability. Integration. Escola de Engenharia UFRGS. Engineering education. 